\title{
Uso social, jurídico y político de la jurisprudencia constitucional para la concreción de los derechos y la legitimación de la democracia en Ecuador
}

\section{Social, legal and political use of constitutional jurisprudence for the realization of rights and the legitimization of democracy in Ecuador}

Xavier Rodas Garcés

Universidad de La Habana, Cuba

Universidad de Guayaquil, Ecuador

Édgar Larco Camacho

Universidad Internacional del Ecuador, Ecuador

Universidad de Guayaquil, Ecuador

Autor para correspondencia: edlarcoca@uide.edu.ec, xavrod7@ hotmail.com

Fecha de recepción: 30 de Junio de 2017 - Fecha de aceptación: 15 de Noviembre de 2017

\begin{abstract}
"La Constitución es simplemente un papel que ha sido fuente de frustración durante mucho tiempo. Varios derechos han sido incluidos pero los pueblos continúan siendo excluidos, empobrecidos, invisibilizados y oprimidos. Estamos ante un nuevo tipo de constitucionalismo que implica un proyecto político de país diferente, otra forma de cultura, de convivencia, de territorialidad, de institucionalidad del Estado".
\end{abstract}

-Boaventura de Sousa Santos-

Resumen: El objetivo general que guía la construcción y sistematización de las ideas que se articulan en este trabajo, apunta a resaltar la necesidad y pertinencia así como identificar factores coadyuvantes y limitantes acerca del uso social, jurídico y político de la jurisprudencia constitucional como instrumento de innovación social y desarrollo a través del sistema de justicia, en el contexto de la institucionalización del conjunto de paradigmas emanados del Texto Fundamental de 2008: el Estado constitucional de derechos y justicia, el neoconstitucionalismo, la constitucionalización del ordenamiento jurídico, la constitucionalización de la justicia y la democracia constitucional, y con sujeción a la premisa respecto de la cual el Derecho surgido a partir de la Constitución de Montecristi, que es un Derecho que deviene constitucionalizado en su integralidad, encierra un enorme potencial emancipatorio y es capaz, bajo determinadas condiciones históricas, sociales y políticas, de promover transformaciones fundamentales en la sociedad. En esta línea de pensamiento, se postula como idea central que la jurisprudencia constitucional, elevada a la categoría de fuente directa del ordenamiento jurídico patrio, es un elemento de innovación social y de desarrollo si y sólo si se le da el uso social, jurídico y político que entraña el Texto Fundamental. La jurisprudencia constitucional, en el nuevo Estado constitucional de derechos y justicia diseñado por la Constitución es un potente instrumento social, político y jurídico en manos de los jueces y de la ciudadanía, para favorecer los cambios y las innovaciones sociales en democracia que comporta el proyecto político transformador contenido en la Carta de Montecristi.

Palabras claves: jurisprudencia constitucional; innovación social y desarrollo; derechos constitucionales; democracia constitucional; administración de justicia; ciudadanía

Abstract: The general objective that guides the construction and systematization of the ideas that are articulated in this work, aims to highlight the need and relevance as well as to identify contributing and limiting factors regarding the social, legal and political use of constitutional jurisprudence as an 
instrument of social innovation and development through the justice system, in the context of the institutionalization of the set of paradigms emanating from the Fundamental Text of 2008: the constitutional State of rights and justice, neoconstitutionalism, the constitutionalization of the legal system, the constitutionalization of justice and the constitutional democracy, and subject to the premise with respect to which the Law emerged from the Constitution of Montecristi, which is a law that becomes constitutionalized in its integrality, has an enormous emancipatory potential and is capable, under certain historical conditions., social and pol ticas, to promote fundamental changes in society. In this line of thought, it is postulated as a central idea that constitutional jurisprudence, elevated to the category of direct source of the national legal order, is an element of social innovation and development if and only if it is given social, legal and social use. that entails the Fundamental Text. Constitutional jurisprudence, in the new constitutional State of rights and justice designed by the Constitution is a powerful social, political and legal instrument in the hands of judges and citizens, to favor the changes and social innovations in democracy that the project entails transforming political content in the Montecristi Charter.

Key words: constitutional jurisprudence; social innovation and development; constitutional rights; constitutional democracy; administration of justice; citizenship

\section{Introducción}

La República del Ecuador experimenta un proceso de hondas transformaciones en su institucionalidad jurídico política a partir del proceso constituyente que hizo posible la entrada en vigencia de la Carta Constitucional de 2008, y con ella, un nuevo modelo de Estado, el Estado constitucional de derechos y justicia, y un nuevo tipo de Derecho, el Derecho constitucionalizado de los valores, los principios, los derechos, las reglas, la ponderación y el pluralismo jurídico.

En efecto, dicha Constitución implicó la entrada del Ecuador al neoconstitucionalismo, que asume un modelo de organización jurídico política denominado Estado c onstitucional, centrado en el principio de supremacía constitucional, la vigencia de los derechos fundamentales y el principio político democrático de soberanía popular, instituye un tribunal especializado para la interpretación y concreción de los preceptos y postulados superiores, la Corte Constitucional, cuyas decisiones son vinculantes como órgano facultado para la producción de normas jurídicas de obligatoria aplicación.

Las decisiones de la Corte Constitucional, de forzoso e inexorable cumplimiento, manifestadas a través de su jurisprudencia, y concretamente, del precedente constitucional, transforma la estructura del sistema de fuentes del derecho, tradicionalmente basado en la fuerza monopólica de la ley ${ }^{1}$. El nuevo modelo establece la sujeción de los jueces, a la jurisprudencia constitucional, por lo que éstos deben interpretar, aplicar y argumentar el derecho no sólo con arreglo a la ley, sino fundamentalmente, en consonancia con la Constitución y la jurisprudencia emanada del máximo órgano de control, interpretación y administración de justicia en materia constitucional, la Corte Constitucional, órgano de cierre del sistema ${ }^{2}$.

\footnotetext{
${ }^{1}$ El legicentrismo ha imperado en el Ecuador durante más de 150 años, desde su fundación como República, lo que ha degenerado en un sistema jurídico caracterizado por el formalismo ético y normativo.

${ }^{2}$ La jurisprudencia ha asumido la altísima tarea de adecuar el Derecho a las exigencias de la nueva sociedad en transformación. La función de los jueces, más que defender una legalidad decrépita, es crear gradualmente la nueva legalidad prometida por la Constitución (Zagrebelsky, G., 2009, Una atormentada apología de la ley, en "Fe en el Derecho", pág. 42, Madrid: Marcial Pons).
} 
Bajo la premisa de que el derecho surgido a partir de la Constitución de 2008 entraña un enorme potencial emancipatorio y es capaz, bajo determinadas condiciones históricas, sociales y políticas, de promover transformaciones fundamentales en la sociedad ${ }^{3}$, el presente ensayo postula como idea central que la jurisprudencia constitucional, elevada a la categoría de fuente formal y directa del ordenamiento jurídico, es un potente elemento de innovación social y de desarrollo sí y sólo sí se le da el uso social, jurídico y político implícito en el Texto Fundamental.

Sin duda, se trata de cambios cualitativos de gran calado que se están verificando en la cultura jurídica nacional, que hace que los juristas debamos aprender a operar bajo estos nuevos paradigmas y necesitemos, en primer lugar, de un enfoque hermenéutico que dé cuenta, desde la perspectiva descolonizadora del poder ${ }^{4}$ y del potencial emancipatorio del derecho ${ }^{5}$, la utilización social, jurídica y política de la jurisprudencia constitucional ${ }^{6}$, como elemento de innovación social, en el contexto de la nueva institucionalidad jurídico política que sobrevino como resultado del proceso constituyente que dio lugar a la Carta de 2008.

Mediante el uso social de la jurisprudencia constitucional, es posible conservar las conquistas sociales y asegurar las transformaciones estructurales en una sociedad profundamente inequitativa, aumentar los niveles de exigibilidad de los derechos y una ciudadanía volcada a vivir realmente los derechos constitucionales, en un proceso permanente de transformación social basado en una política constitucional y una justicia progresista, que materialice los principios y valores de la Constitución, procurando superar la brecha entre las promesas constitucionales y las vivencias cotidianas.

Mediante el uso jurídico, la jurisprudencia constitucional es una herramienta valiosa para garantizar la igualdad procesal, predictibilidad, uniformidad de la actuación de la justicia, la seguridad jurídica, y procurar acercar a la justicia a los problemas concretos e intereses sociales de la población.

Mediante el uso político, los jueces podrán otorgar legitimidad a la democracia, convirtiendo a la justicia en una herramienta dinámica para la materialización de la Constitución, la expansión del contenido esencial de los derechos y las limitaciones al poder.

La pregunta problema sobre la cual giran las reflexiones de este trabajo alude a ¿cuáles son los factores coadyuvantes y limitantes para que la jurisprudencia constitucional, como

\footnotetext{
${ }^{3} \mathrm{El}$ ordenamiento jurídico expresa un producto social al tiempo que actúa como factor social incidiendo sobre la misma sociedad que lo manifiesta (Núñez, M. y Enríquez, G., 2011, La recíproca interacción del derecho, las ciencias y las humanidades como consecuencia del paradigma constitucional, en "Derecho y Política", pág. 115, México: Edit. Novum).

${ }^{4}$ Tesis que plantea, desde la perspectiva del análisis de la colonialidad del poder, la necesidad de superar la dominación neocolonial que ha construido subjetividades, mentalidades, discursos e imaginarios desde los centros del poder hegemónico en el mundo, lo que ha conllevado a supeditar las formas de pensar y actuar, a los intereses de las potencias centrales y a sus modelos culturales.

${ }^{5}$ Permite entender al derecho no solo como instrumento de legitimación del estado de cosas, sino como praxis de la vida de los pueblos y herramienta fundamental para promover y viabilizar profundas transformaciones sociales $\mathrm{y}$ culturales.

${ }^{6}$ ÁVILA, Luis Fernando (2013), Usos de la jurisprudencia constitucional desde el derecho y la justicia del siglo XXI, Bogotá: Edit. Ibáñez.
} 
instrumento de innovación social y desarrollo sea utilizada en la concreción de los derechos y en la legitimación de la democracia a través del sistema de justicia en el Ecuador?

La idea a defender parte de la consideración respecto a que, en el marco de las transformaciones sustanciales del ordenamiento jurídico que alienta la Constitución de 2008 y la asunción de la jurisprudencia constitucional como fuente formal y directa del derecho y su uso social, jurídico y político, es posible promover procesos de innovación social y desarrollo, para favorecer la plasmación en la práctica de los derechos y el modelo de democracia inclusiva y participativa consagrados en el proyecto histórico reivindicatorio contenido en la Carta Constitucional, si y solo si, el sistema de justicia ${ }^{7}$ y la ciudadanía ${ }^{8}$ logran empoderarse de las virtualidades de esta herramienta jurídico política y la hacen suya en la cotidianidad de las relaciones jurídicas y de los procesos sociales de la Nación.

El objetivo general que guía la construcción de las ideas que se articulan en este ensayo, apunta a identificar factores coadyuvantes y limitantes para el uso social, jurídico y político de la jurisprudencia constitucional como instrumento pertinente y necesario para la innovación social y el desarrollo ${ }^{9}$, a través del sistema de justicia, en el contex to de la institucionalización del conjunto de paradigmas emanados de la Constitución de 2008: el Estado constitucional de derechos y justicia, el neoconstitucionalismo, la constitucionalización del ordenamiento jurídico y la constitucionalización de la justicia.

El enfoque metodológico se fundamenta en la teoría crítica del derecho ${ }^{10}$ que hace posible efectuar el análisis de las bases culturales y el contexto histórico, social y político de las transformaciones jurídicas operadas en el Ecuador a partir del proceso constituyente que puso en vigencia al Texto Fundamental del $2008^{11}$, factores que han influido paulatinamente en las nuevas orientaciones acerca de la forma de ver y practicar el derecho y en la configuración de la nueva cultura jurídica nacional.

\footnotetext{
${ }^{7}$ Desde la entrada en vigencia de la Constitución de 2008 se alude a la "constitucionalización de la justicia", para significar la subordinación del quehacer de la administración de justicia al servicio de los postulados, principios, valores, derechos, garantías y libertades prescritos en el Texto Fundamental.

8 Se invoca también el concepto de "ciudadanización de la Constitución", como metodología orientada a institucionalizar y legitimar socialmente el proyecto jurídico político ínsito en la Constitución de 2008.

${ }^{9}$ Se trata de conectar los cambios en el orden jurídico político emanados de la Constitución de 2008, con las consecuentes mutaciones sociales e institucionales mediante el involucramiento de todo el tejido de la sociedad, en dirección a la atención de las necesidades humanas básicas de la población nacional y la participación pública en el proceso de transformaciones del derecho como praxis de vida del pueblo ecuatoriano.

${ }^{10}$ La Teoría Crítica del Derecho es el conjunto de ideas que explican los efectos sociales y los entramados políticos de la praxis jurídica; se orienta a la aprehensión de las condiciones históricas y las estructuras político sociales que confluyen en el estudio del derecho. Hace uso de categorías materialistas con el fin de penetrar en la comprensión profunda de la naturaleza y del rol del derecho. Pretende demostrar que son las condiciones históricas materiales de la vida social las que explican las formas y funciones de las instituciones jurídicas. Para esta corriente de pensamiento, el derecho es una práctica social específica que expresa los niveles de acuerdo y de conflicto de los grupos sociales que operan al interior de una formación económica social determinada, práctica de naturaleza discursiva, discurso ideológico y discurso del poder (Bonetto, M y Piñero, María, Teoría crítica del Derecho).

${ }^{11}$ El día 15 de abril de 2007, mediante Consulta Popular, el pueblo ecuatoriano expresó su voluntad de convocar a una Asamblea Constituyente, con el propósito de elaborar una nueva Constitución y transformar el marco institucional del Estado. El día 28 de septiembre de 2008, mediante referéndum, se aprobó la Constitución. El día 20 de octubre de 2008 entró en vigencia a través de su publicación en el Registro Oficial 451 la Constitución aprobada por el pueblo ecuatoriano.
} 
La metodología de investigación aplicada a este ensayo sobre la jurisprudencia constitucional como elemento de innovación social y desarrollo, se aparta de la reducción normativista del positivismo que ha colonizado el estudio del derecho en nuestro país (Salamanca, 2015), para incursionar en el ámbito de la fundamentación del nuevo paradigma constitucional y el análisis de la realidad jurídica actual del Ecuador, desde perspectivas epistemológicas, gnoseológicas y ontológicas de ese fenómeno cultural que entraña el posicionamiento de la jurisprudencia constitucional como fuente directa del derecho y su uso social, jurídico y político, concebida en la Carta para materializar los principios y valores del constitucionalismo y de la justicia sustancial, haciendo énfasis en el potencial emancipatorio del Derecho, según la concepción del proyecto político gestado en el Ecuador a partir del $2007^{12}$.

El carácter complejo y dialéctico de la realidad jurídica producto de las transformaciones que comporta la institucionalización de la jurisprudencia constitucional, su incidencia en la estructura del sistema de fuentes del derecho y el rol de los jueces en la concreción de los derechos y la legitimación de la democracia, es analizado desde dimensiones históricas, sociológicas, ideológicas, axiológicas y normativas, bajo una concepción del derecho como relación social histórico-jurídica ${ }^{13}$.

La metodología aplicada se despliega desde perspectivas dogmático jurídicas, sociohistórico jurídicas, axiológico jurídicas e ideológico jurídicas, es decir, a través de un enfoque sistémico, multidimensional, e interdisciplinario, que supera la reducción normativista del positivismo y la tradicional exégesis que le acompaña ${ }^{14}$, y da cuenta, en cambio, de la realidad del derecho en el Ecuador en el contexto histórico político del proyecto constitucional del 2008, su dinamismo histórico y su potencial emancipatorio. El enfoque metodológico es integrador y holístico, se orienta al conocimiento dialéctico de la totalidad del fenómeno en estudio, aplica el paradigma de la complejidad y de la articulación sistémica, y siempre bajo una concepción del derecho como praxis social compleja (acción) de la vida de los pueblos y el reconocimiento de su potencial transformador.

El trabajo se orienta a señalar pautas para fortalecer la política pública de promoción de la jurisprudencia constitucional como elemento de innovación social y desarrollo, identificando actores y roles que hagan posible materializar su uso social, jurídico y político, a través del sistema de justicia, en el marco de las profundas transformaciones del Estado y del Derecho que alienta la Constitución de Montecristi.

\footnotetext{
${ }^{12}$ La Constitución surgida y legitimada por el proceso constituyente iniciado en el 2007, plantea como objetivo estratégico de Nación, el "buen vivir". Para el efecto, consagra un conjunto de "derechos del buen vivir". Y para que éstos tengan cumplida realización, instituye el denominado "régimen del buen vivir" (conjunto articulado y coordinado de sistemas, instituciones, políticas, normas, programas y servicios que aseguran los derechos) y como medio de viabilización, el llamado "régimen de desarrollo para el buen vivir" (conjunto organizado, sostenible y dinámico de los sistemas económicos, políticos, socioculturales y ambientales, que garantizan la realización del buen vivir).

13 Superación de la tradicional concepción normativista a que nos redujo el positivismo jurídico, para plantear la ineludible expresión jurídica de la praxis político moral y el dinamismo revolucionario de la praxis jurídica.

${ }^{14} \mathrm{El}$ problema del formalismo jurídico ha sido una constante en la cultura del constitucionalismo ecuatoriano. La ciencia jurídica y los juristas han generado muy poca producción analítica y crítica para ampliar las fronteras del conocimiento jurídico. Poco se ha reflexionado, desde perspectivas multidimensionales, sobre las implicaciones del cambio constitucional operado a partir del 2008. Los estudios se contraen, por lo general, a la sola realización de exégesis normativas del Texto constitucional.
} 


\section{Nuevos paradigmas del ordenamiento jurídico ecuatoriano.}

La Constitución de 2008 con su fuerza normativa y eficacia directa, el Estado constitucional de derechos y justicia, la constitucionalización integral del ordenamiento jurídico en su conjunto, el neoconstitucionalismo, la constitucionalización de la justicia, así como el rol protagónico de la Corte Constitucional como máximo órgano de control, interpretación y administración de justicia en materia constitucional, cuyas decisiones a través de dictámenes y sentencias tienen carácter vinculante y modifican sustancialmente la estructura del sistema de fuentes, son los nuevos paradigmas que han venido a provocar transformaciones radicales en el derecho ecuatoriano, en su concepción y praxis, aspectos esenciales sobre los cuales, y en primer lugar, este ensayo se propone reflexionar, analizar, sistematizar y evaluar con el auxilio de los diversos lentes o enfoques de la doctrina.

El neoconstitucionalismo es la concepción jurídica que orienta al nuevo Derecho, pues según la propia Corte Constitucional, con la entrada en vigencia de la Constitución de 2008, se operó en el Ecuador "la adopción del neoconstitucionalismo como ideología de Estado"15. Esta corriente del pensamiento iusfilosófico comporta un modelo de organización jurídico política denominado Estado Constitucional, cuyas características esenciales se centranj en el principio de supremacía constitucional, la vigencia de los derechos fundamentales y el principio democrático de soberanía popular. El modelo creado instituye un tribunal especializado para la interpretación y concreción de los principios y valores de la Constitución, la Corte Constitucional, cuyas decisiones son vinculantes, erigiéndose en órgano facultado para la producción de normas jurídicas de obligatoria aplicación. Y al definir el Texto Fundamental al Ecuador como Estado constitucional de derechos y justicia, se provoca en criterio de la Corte, un tránsito institucional que ubica al país dentro del "paradigma del neoconstitucionalismo latinoamericano"16, implicando "toda una revolución conceptual y doctrinaria”. El Estado constitucional de derechos implica - para esta misma tesis- una reformulación, desde sus bases hasta sus objetivos más elevados y determinantes de lo que es el derecho en su naturaleza y génesis, en su interpretación y aplicación, incluyendo las fuentes, la hermenéutica, el rol del Estado en el ordenamiento jurídico, las conexiones con la sociedad civil en democracia, la interpretación del orden jurídico con el internacional y otros vectores de semejante importancia ${ }^{17}$.

\footnotetext{
${ }^{15}$ Corte Constitucional, sentencia interpretativa 001-08-SI-CC, R.O 479, de 02-10-2008, p. 15.

${ }^{16}$ El nuevo constitucionalismo latinoamericano expresado en las nuevas constituciones de América Latina defiende que el contenido de la Constitución debe ser coherente con su fundamentación democrática, es decir, que debe generar mecanismos para la directa participación política de la ciudadanía, garantizar la totalidad de los derechos fundamentales incluidos los sociales y los económicos, establecer procedimientos de control de la constitucionalidad que pueden ser activados por la ciudadanía y generar reglas limitativas del poder político pero también de los poderes sociales, económicos o culturales que, producto de la historia, también limitan el fundamento democrático de la vida social y los derechos y libertades de la ciudadanía (Viciano R. y Martínez R, 2010, "Aspectos generales del nuevo constitucionalismo latinoamericano", p.19). Se caracteriza por ser un proceso de renovación y fortalecimiento del constitucionalismo, de dinamismo creativo y de autenticidad democrática de los supuestos constituyentes; acentuación progresiva de la normatividad, especialmente significativa en un ámbito propenso al desorden constitucional del poder y de la vida política que autorizaba a considerarlo como constitucionalismo semántico; eficacia y fuerza creciente de la defensa de la Constitución, potenciada por la conciencia generalizada de su relevancia para realizar el programa social de las mayorías (Del Cabo Martín, C., 2010, Dialéctica del sujeto, dialéctica de la Constitución, pág. 142, Madrid: Editorial Trotta).

${ }^{17}$ Corte Constitucional, sentencia interpretativa 001-08-SI-CC, R.O 479, de 02-10-2008, p. 12.
} 
Dada esta realidad que innova radicalmente al sistema jurídico nacional, puesto que una fue la concepción y la práctica del derecho antes de la Constitución de 2008, y otra, desde la vigencia de la nueva $\operatorname{Carta}^{18}$, es necesario auxiliarnos en los posicionamientos teóricos más relevantes de la doctrina, para caracterizar y explicar los rasgos que definen y fundamentan el perfil neoconstitucionalista del nuevo ordenamiento jurídico surgido con la nueva Constitución.

Así, Miguel Carbonell (2010) plantea tres distintos niveles de análisis en torno al tema; primero: el neoconstitucionalismo pretende explicar un conjunto de textos constitucionales que comienzan a surgir después de la Segunda Guerra Mundial y sobre todo a partir de los años setenta del siglo XX; se trata de constituciones que no se limitan a establecer competencias o a separar a los poderes públicos, sino que contienen altos niveles de normas "materiales" o sustantivas que condicionan la actuación del Estado por medio de la ordenación de ciertos fines y objetivos alrededor de amplios catálogos de derechos fundamentales; segundo: la práctica jurisprudencial de muchos tribunales y cortes constitucionales ha ido cambiando de forma relevante; los jueces constitucionales han tenido que aprender a realizar su función bajo parámetros interpretativos nuevos, a partir de los cuales el razonamiento judicial se hace más complejo, puesto que entran en juego las técnicas interpretativas propias de los principios constitucionales, la ponderación, la proporcionalidad, la razonabilidad, la maximización de los efectos normativos de los derechos fundamentales, el efecto irradiación, la proyección horizontal de los derechos, el principio pro personae, etc.; los jueces tienen que trabajar con "valores" que están constitucionalizados y que requieren de una tarea hermenéutica que sea capaz de aplicarlos a los casos concretos de forma justificada y razonable, dotándolos de esa manera de contenidos normativos concretos; tercero: los desarrollos teóricos novedosos que parten de los textos constitucionales fuertemente sustantivos y de la práctica jurisprudencial marcadamente activista, pero también aportaciones de frontera que contribuyen en ocasiones no sólo a explicar un fenómeno jurídico, sino incluso a crearlo: son importantes a este respecto, los desarrollos teóricos de Ronald Dworkin, Robert Alexy, Gustavo Zagrebelsky, Carlos Nino, Luis Prieto Sanchís, Manuel Atienza y Luigi Ferrajoli, entre otros.

Por su parte Luis Prieto Sanchís, citado por Carlos Bernal Pulido (2007), caracteriza al neoconstitucionalismo a partir de la defensa simultánea de las siguientes tesis atinentes a la Constitución y a su interpretación: la Constitución es material, garantizada, omnipresente, establece una regulación principialista, se aplica mediante la ponderación y presupone un modelo argumentativo de relaciones entre la Constitución y la legislación. Analiza al neoconstitucionalismo a través de tres dimensiones: como filosofía política o doctrina del Estado justo, como una profunda renovación de la teoría del derecho positivista, y como una propuesta de posible conexión entre derecho y moral. Y en esa misma línea de pensamiento Bernal Pulido (2008) precisa como núcleo de aquello que se presenta como neoconstitucionalismo: que los

\footnotetext{
${ }^{18} \mathrm{El}$ ordenamiento jurídico ecuatoriano, desde sus orígenes, fue influenciado por el paradigma del legicentrismo, de origen romano francés, al amparo de dos conceptos básicos: el Estado de derecho y la primacía de la ley frente a la administración, la jurisdicción y los propios ciudadanos. Todo ha girado alrededor de la ley como acto supremo e irresistible, al que no se le opone un derecho más fuerte, cualquiera sea su forma o fundamento y la fuente principal de producción de derecho ha sido el parlamento, a través del procedimiento legislativo, y la ley como encarnación paradigmática de la voluntad general, la manifestación de la normativa por antonomasia (Montaña, J., 2012, El sistema de fuentes del derecho en el nuevo constitucionalismo latinoamericano, en "Apuntes del Derecho Procesal Constitucional", tomo 1, pág. 91, Quito: Corte Constitucional).
} 
derechos fundamentales de la Constitución son principios que se aplican judicialmente mediante la ponderación.

Para Paolo Comanducci (2009) el neoconstitucionalismo es el modelo constitucional que recoge un conjunto de mecanismos normativos e institucionales integrados en un sistema jurídico político históricamente determinado, que limitan los poderes del Estado y protegen los derechos fundamentales. Es concebido como teoría del derecho, ideología del derecho y método de análisis del derecho. Como teoría del derecho, preconiza un modelo de sistema jurídico caracterizado por una Constitución invasora ("constitucionalización del derecho"), la positivización de un catálogo de derechos fundamentales, la omnipresencia en la Constitución de principios y reglas y por algunas peculiaridades de la interpretación y de la aplicación de las normas constitucionales respecto a la interpretación y a la aplicación de la Ley; representa una alternativa respecto a la teoría iuspositivista tradicional basada en el legiscentrismo y el formalismo interpretativo y destaca la fuerza normativa de la Constitución; los rasgos sobresalientes del neoconstitucionalismo como teoría del derecho son: más principios que reglas, más ponderación que subsunción, omnipresencia de la Constitución en todas las áreas jurídicas y en todos los conflictos mínimamente relevantes, omnipotencia judicial en lugar de autonomía del legislador ordinario y coexistencia de una constelación plural de valores. Como ideología, el neoconstitucionalismo pone en primer plano el objetivo de garantizar los derechos fundamentales, a diferencia de la ideología del constitucionalismo clásico que perseguía como objetivo la limitación del poder estatal; subraya la importancia de los mecanismos institucionales de tutela de los derechos fundamentales exigiendo que las actividades del legislativo y del judicial estén directamente encaminados a concretar, actuar y garantizar los derechos fundamentales previstos en la Constitución. Como metodología sostiene la tesis de la conexión necesaria, identificativa y justificativa entre derecho y moral; considera los principios constitucionales como puente entre el derecho y la moral; y, en este sentido, cualquier decisión jurídica y en particular la decisión judicial, estará justificada si se deriva, en última instancia, de una norma moral.

Andrés Gil Domínguez (2009) construye su visión sobre el neoconstitucionalismo como teoría, dogmática, ideología y estilo de vida, al tiempo que presenta una serie de elementos estructurales que lo configuran como paradigma que explican su funcionamiento. Lo define como cierto modelo de Estado de Derecho que concibe institucionalmente una determinada forma de organización política. El neoconstitucionalismo se caracteriza por una Constitución transformadora que pretende condicionar de modo importante las decisiones de la mayoría, donde el protagonismo fundamental ha de seguir correspondiendo al legislador democrático, pero donde irremediablemente la última palabra se encomienda a los jueces.

A partir de los referentes y estándares invocados, recogidos de la doctrina, se precisa discernir si efectivamente el canon neoconstitucional se ha instaurado en el derecho ecuatoriano desde la vigencia de la Constitución de 2008, y a este respecto, debe examinarse las siguientes evidencias relativas al nuevo Texto Fundamental: i) no se limita a la diagramación del poder sino que contiene un ambicioso catálogo de principios y derechos a los que se reviste del carácter de inalienables, irrenunciables, indivisibles, interdependientes y de igual jerarquía, al tiempo que sistematiza y articula un amplio espectro de normas materiales o sustantivas que condicionan la actuación del Estado hacia el objetivo estratégico del buen vivir, los derechos del buen vivir, el 
régimen del buen vivir y el régimen de desarrollo para hacerlos posible, así como establece como el más alto deber del Estado, el de respetar y hacer respetar los derechos garantizados en la Constitución; ii) establece un conjunto de garantías para asegurar su supremacía y los derechos en ella consagrados: garantías normativas, institucionales y jurisdiccionales; iii) define al Ecuador como Estado constitucional de derechos y justicia, social y democrático, por lo que se adhiere a la corriente filosófica, jurídica y política del Estado justo, la tutela fuerte de los derechos, la fuerza normativa de la Constitución y el principio democrático de soberanía popular; iv) está dotado de un conjunto amplio de principios así como de reglas, que articulan valores jurídicos y éticos, en perspectiva identificativa y justificativa entre derecho y moral.

Al juzgar, pues, por estos rasgos distintivos de la Constitución, puede concluirse que efectivamente, el ordenamiento jurídico del Ecuador se ha alineado en la matriz ideológica del neoconstitucionalismo, y que se ha operado, por tanto, la recepción de sus principios por parte del sistema jurídico nacional, abriendo cauces diferentes para estudiar, comprender, interpretar y vivir el derecho, superando la tradición positivista.

El Estado constitucional es el modelo jurídico político que adopta la Constitución para el Ecuador. Corresponde también, en este punto, con auxilio de la doctrina, desentrañar los rasgos fundamentales que comporta esta organización estadual. Según Antonio M. Peña (1997) podemos definir inicialmente al estado constitucional de derecho a partir de tres factores relevantes: la supremacía constitucional y la prevalencia de los derechos fundamentales; la consagración del principio de legalidad como sometimiento efectivo al derecho de todos los poderes públicos; y, la funcionalización de todos los poderes del Estado a la garantía del disfrute y a la efectividad de los derechos. El paso del Estado legislativo (sometimiento del poder público a la ley) al Estado constitucional presupone la afirmación del carácter normativo de las constituciones, que pasarán a integrar un plano de juridicidad superior, vinculante e indisponible, en línea de principio, para todos los poderes del Estado. Las normas constitucionales son vinculantes - de modo que queda definitivamente superada la imagen débil de la juridicidad constitucional característica del período liberal- al ser situadas por encima de los poderes del Estado y fuera del campo de acción y pugna política.

Peter Häberle (2009), por su parte, sostiene como elementos constitutivos del Estado constitucional, antes que nada, a los derechos de igualdad y de libertad que se derivan de la dignidad de la persona: garantizan la apertura del ordenamiento y del proceso político desde el ciudadano.

Luis Prieto Sanchís (2013) señala como rasgos singulares del Estado constitucional de derecho y como novedades que aporta este modelo: el reconocimiento de la incuestionable fuerza normativa de la Constitución; la rematerialización constitucional; la garantía judicial y la aplicación directa de la Constitución; y, la rigidez constitucional.

Para Andrés Gil Domínguez (2009), en el modelo de Estado constitucional de derecho se propone un paradigma distinto al del Estado liberal del siglo XIX y primera mitad del siglo XX, a partir de la reafirmación -mediante la Constitución- del principio de la soberanía popular y la eliminación del principio de la soberanía del Estado, expandiendo su esfera hacia los derechos económicos, sociales y culturales, como así también hacia los derechos colectivos. En este 
paradigma la Constitución se concibe como un mecanismo dirigido a la protección de los derechos y también se proyecta como una gran norma directiva que compromete solidariamente a todos en la obra dinámica de la eficaz realización de los objetivos constitucionales.

Ramiro Ávila Santamaría (2009), postula que el nuevo modelo de Estado constitucional de derechos y justicia instituido por la Constitución ecuatoriana, permite visualizar las innovaciones en dos áreas: la teoría del derecho y el modelo político de Estado. El Estado constitucional nos ayuda a responder quién es la autoridad, cómo se hacen las normas y qué contenido deben tener éstas. El Estado de derechos nos da luces para responder dónde encontramos las nomas y para qué se las expide. El Estado de justicia nos resuelve el problema del por qué el Estado.

Santiago Andrade Ubidia (2009), al referirse a la caracterización del Estado constitucional de derechos y justicia que consagra la Constitución del Ecuador, señala que se ha transitado del principio de legalidad al de constitucionalidad; ha concluido el monopolio del sistema jurídico de ley escrita estructurado bajo el modelo continental puesto que junto a este sistema existen otros que tienen igual reconocimiento y validez; el Estado se organiza y funciona a fin de realizar la justicia social, que en definitiva es la justicia para todas y todos; y, se debe garantizar en todo momento la vigencia de los derechos humanos: esto último constituye el eje central del actuar íntegro del Estado.

La Corte Constitucional del Ecuador sistematiza los siguientes rasgos característicos del Estado constitucional de derechos y justicia que proclama el Art. 1 de la Constitución de Montecristi: a) la existencia de una Constitución no modificable por medio de la ley; b) el carácter normativo y la fuerza vinculante de toda la Constitución; c) el control judicial de la constitucionalidad, a través de la existencia de garantías jurisdiccionales que permiten vigilar la conformidad de las normas infra constitucionales respecto de la Constitución; d) la directa aplicación de la Constitución para resolver todos los conflictos jurídicos que se presentan en la sociedad; y, e) la facultad de interpretar todo el ordenamiento, a la luz de la Constitución, a través de un órgano especializado del poder público denominado Tribunal o Corte Constitucional"19.

Para la Corte, tres efectos esenciales entraña el nuevo modelo de Estado constitucional de derechos y justicia: el reconocimiento de la Constitución como norma vinculante, valores, principios y reglas constitucionales; el tránsito de un juez mecánico aplicador de reglas a un juez garante de la democracia constitucional y de los contenidos axiológicos previstos en la Constitución; la existencia de garantías jurisdiccionales vinculantes, adecuadas y eficaces para la protección de todos los derechos constitucionales ${ }^{20}$. El Estado Constitucional supone "la aproximación máxima a la que ha llegado en la materialización del ideal jurídico de la civilización occidental, esto es, el ejercicio de los derechos que se imponen a la voluntad de quienes tienen el poder", ha dicho con especial énfasis la Corte Constitucional del Ecuador ${ }^{21}$.

\footnotetext{
${ }^{19}$ Corte Constitucional de Transición: Sentencia interpretativa 001-08-SI-CC, R.O., 479-S-, 2-XII-2008, p. 14.

${ }^{20}$ Corte Constitucional de Transición: Sentencia de jurisprudencia vinculante 001-10-PJO-CC., R.O.No.351-S- de 29-XII-2010, p. 4.

${ }^{21}$ Corte Constitucional de Transición: Sentencia Interpretativa 001-08-SI-CC, R.O., 479-S-, 2-XII-2008, p. 12.
} 
En resumen, son elementos básicos que configuran al Estado Constitucional diseñado por el Texto Fundamental de 2008: i) la supremacía de la Constitución o reconocimiento de su carácter normativo superior; ii) la aplicación directa de la Constitución como norma jurídica; iii) la garantía reforzada de los derechos; iv) el funcionamiento de una justicia especializada para los conflictos de orden constitucional; y, v) el reconocimiento de la jurisprudencia constitucional como fuente primaria del derecho.

En el caso de las vivencias del modelo de Estado constitucional se concluye que la Constitución ha dejado de ser un programa político y se ha convertido en una norma jurídica de aplicación directa e inmediata y de favorabilidad de la efectiva vigencia de los derechos y sus garantías. Los derechos son enfocados como sinónimo de pluralismo jurídico y centralidad del ordenamiento jurídico y del sistema de justicia. Se ha operado el tránsito del principio de legalidad al principio de constitucionalidad, del monopolio jurídico al pluralismo jurídico. El Estado se encuentra organizado y funcionando, según el diseño constitucional, para la realización de los derechos humanos, con el específico deber de garantizar, sin discriminación alguna, el efectivo goce de los derechos establecidos en la Constitución y en los instrumentos internacionales cumpliendo con su más alto deber, el respetar y hacer respetar los derechos garantizados en la Constitución ${ }^{22}$. El rol del juez es el de creador de derecho y garante de los derechos. La justicia es la plasmación en la práctica de los derechos fundamentales ${ }^{23}$.

La constitucionalización del ordenamiento jurídico es inherente al neoconstitucionalismo y a su modelo de organización jurídico política, el Estado Constitucional, fenómeno que según R. Guastini (2010) opera como el proceso de transformación de un ordenamiento jurídico, al término del cual, el ordenamiento en cuestión resulta totalmente "impregnado" de las normas constitucionales. Para Guastini, las principales condiciones de constitucionalización son: existencia de una Constitución rígida, que incorpora los derechos fundamentales; garantía jurisdiccional de la Constitución; fuerza vinculante de la Constitución (que no es un conjunto de normas "programáticas" sino "preceptivas"); "sobreinterpretación" de la Constitución (se la interpreta extensivamente y de ella se deducen principios implícitos); aplicación directa de las normas constitucionales, también para regular las relaciones entre particulares; interpretación adecuadora de las leyes.

Un ordenamiento jurídico se encuentra constitucionalizado en circunstancias que la Ley Fundamental resulta extremadamente invasora, entrometida, capaz de condicionar tanto la legislación como la jurisprudencia y el estilo doctrinal, la acción de los actores políticos así como las relaciones sociales, por lo que son rasgos característicos del ordenamiento jurídico constitucionalizado: la rigidez y la garantía jurisdiccional de la Constitución, su fuerza vinculante, la sobreinterpretación constitucional, la aplicación directa de las normas constitucionales, la interpretación conforme de las leyes y la influencia de la Constitución sobre las relaciones políticas.

\footnotetext{
${ }^{22}$ Constitución de la República, art. 3 num.1; art. 11 num. 9.

${ }^{23}$ Al definir la Constitución al Ecuador como" Estado constitucional de derechos y justicia” (art.1), asume el concepto de justicia como sinónimo de plena vigencia práctica de los derechos, que se operativiza a través del aparato de administración de justicia, por lo que los jueces son tenidos como instrumento para este propósito constitucional.
} 
En este mismo sentido destaca Luis Prieto Sanchís (2005), bajo la categoría de constitucionalismo fuerte, cuatro rasgos básicos: la Constitución es considerada como norma jurídica y no un catecismo moral o político, que vincula a sus destinatarios; además de norma formal o procedimental, la Constitución incorpora un denso contenido sustantivo formado por principios, valores, derechos fundamentales, directrices, etc., esto es, que la Constitución no sólo establece quién manda y cómo se manda, sino que pretende condicionar también en una amplia medida qué puede o debe mandarse; la tutela de las normas constitucionales y, en particular, de los derechos corresponde a la justicia como institución encargada de brindar las correspondientes garantías secundarias para la anulación de los actos inválidos y la condena de los actos ilícitos realizados en violación de cualquier norma primaria; y, la Constitución habla de demasiadas cosas, lo hace en ocasiones con no poca imprecisión, se dirige a todos y no solo a las instituciones.

Con sujeción a los estándares reseñados, puede afirmarse que efectivamente el ordenamiento jurídico ecuatoriano, a partir de la Carta Fundamental de 2008 se encuentra constitucionalizado, en refuerzo de cuyo planteamiento cabe señalar: i) la normativa infraconstitucional emanada tanto del órgano parlamentario como de otros órganos de la institucionalidad estatal, durante la vigencia de la Constitución de 2008, recogen por lo general, de manera sistemática y profusa los postulados esenciales de la Norma Suprema; ii) la invocación de preceptos constitucionales es por regla común, el modo argumentativo y justificativo de todo acto normativo, administrativo o jurisdiccional de los competentes órganos del poder público; iii) se establece procedimientos especiales para la producción de innovaciones del texto constitucional (enmienda, reforma parcial y asamblea constituyente), por lo que el sistema dota a la Constitución de una rigidez reforzada para garantizar la estabilidad y permanencia de los objetivos esenciales del poder constituyente; iv) la Constitución se halla jurisdiccionalmente garantizada, y al efecto se ha diagramado todo un complejo orgánico procesal para la justicia constitucional, orientado a precautelar tanto el principio de supremacía constitucional como la vigencia plena de los derechos fundamentales, otorgando a todo ciudadano la potestad para que, de manera individual o colectiva, ejerza las acciones de inconstitucionalidad o de garantía de los derechos; v) se proclama de manera expresa, la fuerza vinculante y la aplicación directa de la Constitución, cuyos preceptos obligan a toda persona, autoridad e institución y exigen de jueces y agentes de la administración pública, su inmediata e incondicional ejecución; v) el ámbito dispositivo y normativo de la Constitución alcanza también a las relaciones entre particulares, por lo que cabe hablar también de la constitucionalización de derecho privado; vi) la Constitución está poblada de regulaciones que condicionan de uno u otro modo, la actuación de la legislación, la jurisprudencia, los desarrollos doctrinales, la acción de los actores políticos y de las relaciones sociales; toda actuación tanto del poder público como de los particulares es evaluada bajo el prisma de los preceptos constitucionales; y vi) se trata de una Constitución actuante y viviente, a diferencia de la vigencia precaria y condicionada que tuvieron las Cartas Políticas anteriores al 2008.

La fuerza normativa y la eficacia directa de la Constitución es el signo distintivo del neoconstitucionalismo; la eficacia normativa y la aplicación directa de la Constitución son pilares fundamentales del nuevo paradigma constitucional. En el neoconstitucionalismo, la Constitución tiene verdadero carácter de norma, por lo que su aplicación directa por parte de legisladores, jueces y administradores, es obligatoria. La eficacia directa significa que todos los 
llamados a aplicar el derecho deberán tomar la norma constitucional como una premisa de su decisión. La Constitución no sólo es norma sobre las normas sino norma aplicable, no será sólo fuente sobre la producción sino también fuente de derecho sin más. La Constitución será directamente aplicable por cualquier servidor público, jueces y tribunales sin necesidad de ningún procedimiento previo de recepción por otra fuente del Derecho, y puede ser directamente invocada o alegada por cualquier persona, sin necesidad de hacerla acompañar de precepto legal alguno. Los derechos que la Constitución reconoce son inmediatamente operativos, aun cuando el legislador no haya procedido a regularlos ${ }^{24}$.

La Corte Constitucional, refiriéndose a la consecuencia jurídica de la transformación a sistema normativo de la Constitución, señala que: “... Esta transformación progresiva de la Constitución hasta llegar a ser una norma, implica, por lo menos, en su fórmula pura, que todos los ciudadanos y operadores jurídicos habrán de tomar el texto íntegro de la Constitución como una premisa de decisión, igual que cualquier otra norma. Lo anterior, como bien señala Ignacio de Otto (Derecho Constitucional, sistema de fuentes), trae sustanciales secuelas frente a la interpretación de la Constitución, a saber: a) habrá de interpretarse todo el ordenamiento jurídico conforme al texto constitucional; b) habrán de examinarse, a la luz del texto constitucional, todas las normas del ordenamiento jurídico, para comprobar si son o no conforme con el texto constitucional y con el llamado doctrinariamente bloque de constitucionalidad; c) en la aplicación concreta del derecho por los diversos operadores jurídicos, deberán aplicar, en primer lugar, la Constitución y las normas que tengan su misma jerarquía, a fin de extraer de ella la solución a cualquier litigio o problema jurídico; y sólo si ésta no dice nada, se aplicarán las normas secundaria; $y, d)$ la condición normativa de la Constitución tiene un efecto derogatorio general y automático para las normas preconstitucionales (ipso constitutione) y en general, previa petición de parte para las normas infraconstitucionales posteriores a la Constitución" 25 .

La consecuencia práctica de la adopción de este modelo constitucional es que todos los funcionarios públicos, incluidos los jueces y los propios particulares, deberán respetar la Constitución y desarrollar sus funciones de conformidad con lo que dice el texto de la Carta Fundamental y las sentencias del órgano encargado de ejercer la justicia constitucional "26. Congruente con ese desarrollo doctrinal, la jurisprudencia de la Corte Constitucional ha establecido, como precedente vinculante, que "la Constitución de la República del Ecuador, para su validez y eficacia, no requiere de desarrollo legal o reglamentario alguno. Sus disposiciones disfrutan de eficacia directa e inmediata" 27.

La constitucionalización de la justicia es el fenómeno que pone de manifiesto el rol esencial del sistema de justicia como instrumento para alcanzar los propósitos constitucionales, en cuya virtud la misión que los jueces están llamados a cumplir en la democracia constitucional, con arreglo a los principios del neoconstitucionalismo y del Estado constitucional, consiste en la

\footnotetext{
${ }^{24}$ El Art. 424 de la Constitución de la República establece que: "La Constitución es la norma suprema y prevalece sobre cualquier otra del ordenamiento jurídico. Las normas y actos del poder público deberán mantener conformidad con las disposiciones constitucionales; en caso contrario carecerán de eficacia".

${ }^{25}$ Corte Constitucional de Transición: Sentencia Interpretativa 001-08-SI-CC, R.O., 479, suplemento, 2-XII-2008, pág. 14.

${ }^{26}$ Ibidem, pág. 14.

${ }^{27}$ Ibidem, Decisión 1, pág. 18.
} 
defensa tenaz, eficaz, activa y operante de los derechos humanos, a fin de materializar su plena vigencia práctica.

A este respecto, Luis Fernando Ávila (2009) considera que el Estado constitucional de derechos y justicia abre en el Ecuador un espacio para la pluralidad de sistemas jurídicos, estatales y no estatales, y al reconocimiento sustancial de los derechos, por tanto, a la “constitucionalización de la administración de justicia” y, a través de ella, a la ampliación de las potencialidades democratizadoras de la sociedad ecuatoriana, y hace notar que el énfasis en la justicia posiciona a "los jueces como garantes de los derechos" frente a la decisión prioritaria de conflictos socialmente relevantes y en la materialización de los derechos en los casos concretos, y permite fundamentar la reforma judicial y las políticas judiciales sobre la base de un "acceso a la justicia sustancial"; puntualiza que la constitucionalización de la administración de justicia "supera la formalidad" y apunta hacia la "creación de una nueva institucionalidad judicial al servicio de la gente que asegure el acceso sustancial a la justicia: la constitucionalización material".

El Estado Constitucional instituido por el Texto Fundamental del Ecuador, a criterio de Santiago Andrade Ubidia (2009) precisa de un nuevo papel para el juez como garante de los derechos humanos reconocidos en la Constitución y en los instrumentos internacionales sobre la materia. En el Estado legalista, la función judicial se limita a una tarea exclusivamente aplicativa de la ley; el derecho una vez creado por el legislador, debe ser aplicado de un modo mecánico por el juez (subsunción). En el Estado constitucional, en cambio, los jueces asumen un papel esencial en el proceso de creación del derecho; las prácticas de los tribunales y los principios y reglas no son una operación de subsunción lógica, sino un proceso de interpretación y argumentación racional de las decisiones sobre la base del sentido común, de los valores, del balance de los intereses políticos y de la idea de justicia imperante en la sociedad. Así, el Estado constitucional de derechos y justicia implica la superación del Estado legalista o de legalidad. La Constitución deja de ser un mero programa político y se convierte en una verdadera norma, no cualquier norma sino en la "norma suprema" del ordenamiento y a partir de allí, disciplina a todos los poderes públicos y a los particulares.

La práctica judicial, a la luz de los principios y valores de la Constitución de 2008 deja de ser una operación de subsunción lógica para convertirse en una operación de argumentación y de interpretación. Se establecen garantías reales de los derechos de las personas a través de un sistema de justicia eficaz, independiente, especializada. Los jueces asumen un papel esencial en el proceso de creación del derecho.

La Constitución, al definir al Estado ecuatoriano como constitucional de derechos y justicia y consagrar como deber primordial del Estado garantizar, sin discriminación alguna, el efectivo goce de los derechos humanos, ha constitucionalizado a la administración de justicia y a la justicia, y ha trazado un nuevo diseño del sistema judicial, donde los jueces son creadores de derecho y garantes de los derechos a través de una justicia restaurativa y distributiva. La actual Constitución prescribe un modelo de poder judicial activista que tutele eficazmente los derechos humanos y como instrumento para materializar el ideal de la justicia. 
La jurisprudencia constitucional es fuente directa y formal del derecho, a partir de la vigencia de la Constitución de $2008^{28}$. La exigencia de respetar la jurisprudencia constitucional es global para todo el sistema jurídico; genera un efecto irradiación respecto a las demás materias. El máximo órgano de control, interpretación y de administración de justicia en materia constitucional produce precedentes obligatorios y vinculantes.

En el análisis del nuevo rol instrumental de la jurisprudencia constitucional y su incidencia en la estructura del sistema de fuentes, Juan Montaña (2012) puntualiza que la Corte Constitucional tiene un papel definitivo en la transformación de las fuentes del derecho, en razón de que la jurisprudencia constitucional está llamada a convertirse en la fuente fundamental de la resolución de los conflictos sociales del país.

La Corte Constitucional del Ecuador ha enfatizado que "todos los funcionarios públicos, incluidos los jueces y los propios particulares, deberán respetar la Constitución y desarrollar sus funciones de conformidad con lo que dice el texto de la Carta Fundamental y las sentencias del órgano encargado de ejercer la justicia constitucional" ${ }^{\text {,29 }}$. Sin embargo, J. Montaña pone de manifiesto algunas dificultades para convertir los fallos de los jueces constitucionales en fuente directa del derecho: las sentencias no consiguen resumir y sintetizar los hechos adecuadamente; no existen criterios claros y homogéneos para el manejo del precedente horizontal; no hay un lenguaje técnico normalizado de cada una de las acciones; no existe doctrina judicial propia para identificar el pensamiento y el enfoque doctrinario que ha desarrollado la Corte; las sentencias abusan de citas doctrinarias extranjeras; existen fallas de argumentación; no hay cadena de argumentos deductivos ni esfuerzos suficientes para indicar las razones de las decisiones; subsisten problemas de registro de las sentencias que hacen muy difícil encontrarlas y utilizarlas... todo lo cual constituye, entre otros factores, verdaderas limitantes para el adecuado uso de la jurisprudencia y la institucionalización de la cultura del precedente como herramienta para favorecer cambios cualitativos fundamentales en los órdenes sociales, jurídicos y políticos.

Luis Fernando Ávila (2008), por su parte, enfatiza en los tres usos que la jurisprudencia constitucional debe tener: político, social y jurídico. Mediante el uso político, los jueces otorgan legitimidad a la democracia y hace posible convertir a la justicia en una herramienta dinámica para la materialización de la Constitución y los límites del poder. El uso social, permite conservar las conquistas sociales y asegurar las transformaciones estructurales en una sociedad profundamente inequitativa, posibilita aumentar los niveles de exigibilidad y una ciudadanía volcada a vivir realmente los derechos constitucionales, en un proceso permanente de transformación social basado en una política constitucional y una justicia progresista, que materialice los principios y valores de la Constitución. El uso jurídico convierte a la jurisprudencia constitucional en una herramienta valiosa para garantizar la igualdad procesal,

\footnotetext{
${ }^{28}$ Con la Constitución de 2008 la estructura del sistema de fuentes del ordenamiento jurídico ecuatoriano ha experimentado un giro de 180 grados: la ley ha dejado lugar a la Constitución y a los instrumentos internacionales de derechos humanos y comparte espacio normativo con la jurisprudencia constitucional que ha pasado a ser fuente formal y directa del Derecho. Con esta innovación, ha cambiado también la estructura institucional del Estado: la legislatura ya no es el único centro o núcleo del sistema jurídico estatal; los jueces dejan de ser la boca muda de la ley y pasan a ser protagonistas del nuevo Estado de justicia y el sistema judicial en su conjunto, instrumento para hacer realidad el modelo constitucional.

${ }^{29}$ Corte Constitucional de Transición: Sentencia Interpretativa 001-08-SI-CC, R.O., 479-S-, 2-XII-2008, p. 14.
} 
predictibilidad, uniformidad de la actuación de la justicia, la seguridad jurídica, y procura acercar a la justicia a los problemas concretos e intereses sociales de la población.

\section{Los derechos.}

Por definición, los derechos fundamentales ocupan la centralidad del ordenamiento jurídico y de la institucionalidad pública en el neoconstitucionalismo, el Estado constitucional y la democracia constitucional, y en la matriz de pensamiento que articula derechos-Constituciónjurisprudencia, Robert Alexy (2008) caracteriza la posición de los derechos en el sistema jurídico a través de cuatro extremos: 1.- el máximo rango, por encontrarse regulados en la Constitución, de lo cual se sigue que toda norma jurídica que los infrinja es inconstitucional y en consecuencia nula por regla general; 2.- la máxima fuerza jurídica, porque vinculan como derecho directamente vigente al Legislativo, al Ejecutivo y al Judicial; no son más meras declaraciones programáticas (o "poesía constitucional”), carentes de tutela judicial, gozan de justiciabilidad plena; el control jurisdiccional se extiende sobre los tres poderes; si antes valía decir: derechos fundamentales sólo en el marco de las leyes, ahora se quiere decir: leyes sólo en el marco de los derechos fundamentales; cada juez debe tener en cuenta en cada decisión los derechos fundamentales, éstos deben irradiar al derecho en su totalidad como valores o "juicios de valor objetivos"; 3.- la máxima importancia del objeto, porque mediante los derechos fundamentales se decide acerca de la estructura básica de la sociedad; 4.- el máximo grado de indeterminación, que se expresa en el carácter sumamente sucinto y desde luego lapidario y vacío de las declaraciones del texto constitucional; los derechos fundamentales son lo que son sobre todo a través de la interpretación de la jurisprudencia.

En definición teórica, puramente formal o estructural, Luigi Ferrajoli (2014) conceptualiza como "derechos fundamentales" todos aquellos derechos subjetivos que corresponden universalmente a "todos" los seres humanos en cuanto dotados del status de personas, de ciudadanos o personas con capacidad de obrar; entendiendo por "derecho subjetivo" cualquier expectativa positiva (de prestaciones) o negativa (de no sufrir lesiones) adscritas a un sujeto por una norma jurídica; y por "status" la condición de un sujeto, prevista asimismo por una norma jurídica positiva, como presupuesto de su idoneidad para ser titular de situaciones jurídicas y/o autor de los actos que son ejercicio de éstas. Ferrajoli postula cuatro tesis en torno a los derechos fundamentales: $1^{a}$, enfatiza la radical diferencia de estructura entre los derechos fundamentales y los derechos patrimoniales, concernientes los unos a enteras clases de sujetos y los otros a cada uno de sus titulares con exclusión de todos los demás; $2^{\mathrm{a}}$, los derechos fundamentales corresponden a intereses y expectativas de todos, forman el fundamento y el parámetro de igualdad jurídica; $3^{\mathrm{a}}$, la naturaleza supranacional de gran parte de los derechos fundamentales; y, $4^{\mathrm{a}}$, las relaciones entre los derechos y sus garantías: primarias y secundarias, las primeras comportan obligaciones de prestación y prohibiciones de lesión, y las segundas, obligaciones de reparar o sancionar judicialmente las lesiones de los derechos, es decir, las violaciones de sus garantías primarias.

Según Giancarlo Rolla (2011), en los últimos años se aprobaron nuevas cartas constitucionales, las cuales -más allá de las especificidades históricas, de la diversidad de las formas de gobierno y de Estado- tienden a homologarse en la lista de los derechos de la persona, reconocidos como fundamentales y en las técnicas de garantía. Las nuevas constituciones tienen 
en común la voluntad de reservar una amplia parte del texto a la enumeración de una vasta gama de derechos fundamentales y a la identificación de instrumentos específicos y órganos para su tutela.

Para Tulio Chinchilla (2009), un derecho es fundamental en la medida que se integra por cinco elementos esenciales sin los cuales tal derecho es impensable como categoría jurídica: el núcleo axiológico que lo fundamenta: valores o principios ético-políticos explícitos o implícitos, de los cuales el derecho es concreción inmediata y necesaria; situación ventajosa, beneficiosa o favorable de la cual alguien puede sacar partido y que se concreta en un conjunto de facultades: libertad de acción, "poder" de limitar la libertad de alguien, legitimidad para reclamar algo a alguien en las relaciones sociales, etc.; un sujeto identificable titular de la situación ventajosa descrita y un sujeto obligado (identificable) sobre el cual recaerán las cargas o limitaciones de conducta que del derecho se deriven; un conjunto de deberes de dar, hacer o no hacer, tanto específicos como generales, que constituyen el correlato obligacional del derecho y que van surgiendo en cada situación fáctica a partir de la afirmación de éste; y, un conjunto de garantías institucionales cualificadas o reforzadas, es decir, diferentes y cualitativamente superiores a las acciones judiciales ordinarias (supergarantías objetivas y subjetivas), que habilitan al titular del derecho a reclamar su respeto por vías coercitivas en caso de vulneración o desconocimiento.

Los derechos humanos, llamados también derechos fundamentales, derechos naturales, derechos públicos subjetivos, libertades públicas, derechos morales, traducen en el fondo, ideales de dignidad, de justicia y de libertad. Están proclamados en instrumentos internacionales y en los textos constitucionales internos. Son en esencia, universales, indivisibles, interdependientes e interrelacionados, progresivos, mejorables, perfectibles, irrenunciables, inalienables, imprescriptibles, protegen a la persona humana y son inherentes o inmanentes a ella.

Un derecho es fundamental a partir de tres significaciones: en el orden moral, significa que ese derecho emana directamente de la dignidad del hombre y es esencial, inherente o inalienable al ser humano (derecho sin el cual el ser humano deja de ser tal, se rebaja en su dignidad o se destruye en su esencia); en el orden político-social, significa que ese derecho representa un pilar sobre el cual descansa y se sostiene el orden de convivencia pacífica y justa ( él se tornaría miserable); y, en el plano técnico-constitucional, ese derecho goza de un conjunto de garantías reforzadas frente a los poderes públicos, aún frente al legislador y frente al poder constituyente. Por otro lado, los derechos fundamentales gozan de las siguientes modalidades garantes: tienen carácter vinculante sobre todos los poderes públicos; son de aplicación directa por los jueces y órganos administrativos; están dotados de la garantía de la reserva de ley; gozan de la garantía del contenido esencial frente al poder legislativo; están garantizados mediante acciones constitucionales; $y$, son protegidos aun frente al poder constituyente secundario.

Antonio Manuel Peña (1997) estima que los derechos fundamentales son la expresión jurídica de los valores y opciones centrales del pacto social, lo que quiere decir que éstos no son sino el fundamento de aquéllos. La principal consecuencia de esta conexión con los valores externos nos lleva a considerar los derechos fundamentales como el vaso comunicante o la correa de transmisión de los valores dimanantes de la centralidad de la persona hacia el resto del orden jurídico-político. 
La Constitución ecuatoriana del 2008 ha recogido la garantía del contenido esencial de los derechos fundamentales, al rescribir que "ninguna norma jurídica podrá restringir el contenido de los derechos ni de las garantías constitucionales" (Art. 11.4); y, "en materia de derechos y garantías constitucionales, las servidoras y servidores públicos, administrativos o judiciales, deberán aplicar la norma y la interpretación que más favorezcan a su efectiva vigencia" (Art. 11.5). Concomitantemente, rodea a los derechos en ella proclamados, de garantías normativas, institucionales y jurisdiccionales, atento el postulando fundamental según el cual el más alto deber del Estado es respetar y hacer respetar los derechos garantizados en la Constitución (Art. 11.9).

\section{Clasificación de los derechos.}

Con relación a la clasificación de los derechos fundamentales, Pedro Néstor Sagüés (2004) hace una explicación de las tres generaciones de derechos reconocidas por la literatura tradicional de los derechos humanos: los derechos de primera generación, característicos del constitucionalismo de la primera etapa de tipo liberal-individualista: derecho de propiedad, derecho de comerciar y de asociarse, derechos de participación política democrática, derecho de expresar libremente las ideas y los cultos, libertad de circulación, igualdad formal ante la ley, derecho al debido proceso, inviolabilidad de domicilio y de la correspondencia, etc.; los derechos de segunda generación, característicos del constitucionalismo social, protector de los trabajadores: derecho al trabajo y al salario digno, descansos y vacaciones pagadas, indemnizaciones por accidentes laborales, acceso a la vivienda y a la salud, derecho de huelga y de agremiarse y de celebrar convenios colectivos de trabajo, derechos que exigen prestaciones por parte del Estado y de los particulares; los derechos de tercera generación, propios del constitucionalismo de fines del siglo XX, como los derechos que amparan al medioambiente y a otros derechos colectivos (patrimonio cultural), a los usuarios o consumidores, a la libre competencia, al niño, a la mujer, a los discapacitados, a la propia imagen y a la autodeterminación informativa, derechos de los pueblos indígenas y ciertas minorías, derecho a la paz, etc. Finalmente, refiere derechos de cuarta generación, en vías de elaboración, referidos a los derechos de las generaciones futuras y derechos de la humanidad en general.

La Constitución ecuatoriana de 2008 reformula la clasificación de los derechos, apartándose de la clásica distinción entre derechos civiles, políticos, económicos, sociales, culturales y colectivos, que constaba hasta la Carta de $1998^{30}$. En efecto, la notable innovación clasificatoria en derechos del buen vivir (agua y alimentación, ambiente sano, comunicación e información, cultura y ciencia, educación, hábitat y vivienda, salud, trabajo y seguridad social), derechos de las personas y grupos de atención prioritaria (adultas y adultos mayores, jóvenes, movilidad, mujeres embarazadas, niñas, niños y adolescentes, personas con discapacidad, personas con enfermedades catastróficas, personas privadas de libertad, personas usuarias y consumidoras), derechos de las comunidades, pueblos y nacionalidades (indígenas, afroecuatorianos, montubios), derechos de participación, derechos de libertad, derechos de la naturaleza y derechos de protección ${ }^{31}$.

\footnotetext{
${ }^{30}$ Constitución de 1998, Art. 23 y ss.

${ }^{31}$ Constitución, desde el artículo 12 hasta el artículo 82, inclusive.
} 
La Carta de Montecristi rompe con la tradición liberal restrictiva de considerar que existían derechos individuales y excepcionalmente, colectivos; ahora esta dicotomía ha sido superada; todos los derechos tienen una doble dimensión: la individual y la colectiva y el Texto Fundamental constituye como titulares a todas las personas, comunidades, pueblos, nacionalidades y colectivos ${ }^{32}$, y se podrán promover y exigir de forma individual y colectiva ${ }^{33}$, por lo que cualquier persona, grupo de personas, comunidad, pueblo o nacionalidad podrá proponer las acciones previstas en la Constitución ${ }^{34}$.

\section{Protección de los derechos.}

El sistema judicial es el instrumento concebido por la Constitución del neoconstitucionalismo y del Estado constitucional, para hacer efectivas las promesas constitucionales y dentro de éstas, el amplio catálogo de derechos. A este respecto, Humberto Nogueira Alcalá (2009) nos ofrece una interesante metodología para la aplicación de los derechos por parte de los jueces: se debe partir por delimitarlos, es decir, determinar sus contenidos y sus límites o fronteras, como asimismo resolver en los casos concretos cuál es ese contenido y límite; la determinación del contenido de un derecho, implica precisar los siguientes elementos: el titular del derecho, los obligados al respeto del derecho, el contenido de la obligación y las circunstancias y condiciones para su aplicación, las facultades que el titular posee en caso del incumplimiento del deber de respeto de su derecho, la especificación de las fronteras o límites internos y externos del derecho para que no se superponga parcialmente con otro derecho, armonizándolos o ajustándolos.

Los límites internos o inmanentes se derivan del sentido y contenido de cada derecho (por ejemplo, en el derecho de libertad de información, sus límites internos son la veracidad y la relevancia pública del asunto informado). Los límites externos, en cambio, están fijados por otros derechos o bienes constitucionales o fijados por el legislador en cuanto regulador y autorizado para restringir el ejercicio de los derechos dentro del ámbito autorizado por la Carta Fundamental; para determinar los límites externos, hay que estudiar en abstracto el derecho infringido por alguna norma, determinando si hay una restricción inconstitucional de tal derecho, si teniendo en cuenta otros bienes constitucionales en juego, la infracción se encuentra justificada, aplicando un test de ponderación, justificando la preferencia de uno sobre el otro en el caso concreto por ser una limitación adecuada en virtud de un principio determinado, por ejemplo: si es proporcionada a un fin legítimo, si es necesaria en una sociedad democrática.

En síntesis, la metodología propuesta por Nogueira, comprende en una primera etapa, el examen solo del contenido inicialmente protegido o prima facie, por el enunciado normativo constitucional del derecho, estableciendo las facultades que se relacionan con el interés protegido por el derecho, sin investigar si tal derecho daña o afecta algún otro derecho o bien constitucionalmente protegido; en una segunda etapa, se establece el contenido definitivamente protegido por el derecho, haciendo intervenir los límites que desde afuera afectan o restringen el derecho, produciéndose un pronunciamiento si hubo o no una injerencia ilícita o si la restricción está justificada y no vulnera al derecho.

\footnotetext{
${ }^{32}$ Constitución, Art. 10.

${ }^{33}$ Constitución, Art. 11 num. 1.

${ }^{34}$ Constitución, Art. 86 num. 1.
} 
La Corte Constitucional del Ecuador, en una de sus sentencias, con acierto precisa que: "El juez constitucional garantiza los derechos humanos, falla sin temor ni esperando favores. Se ampara en una solvencia intelectual y una absoluta independencia frente a los otros poderes del Estado, una probidad moral e imparcialidad que no deberían admitir la más remota sombra de duda, la más minúscula discusión. El verdadero juez garantista no calcula que es lo que puede agradar o disgustar al poder. El juez constitucional sabe que existe un coto vedado, una esfera de lo indecidible; sabe que hay cuestiones propias de la democracia que no se decide en base a un simple y triste procedimiento de contar voluntades. El auténtico letrado garantista no puede ser un siervo obsecuente de los caprichos de un poder del Estado. Eso es lo que todo el Ecuador espera de esta Corte Constitucional" 35.

\section{La democracia.}

El modelo de democracia participativa que diseña la Constitución de 2008, es la democracia constitucional. Con relación a este género de democracia, en cuya matriz conceptual se alinea el modelo instituido por el Texto Fundamental, Luigi Ferrajoli (2011) apunta que es un modelo de democracia fruto de un cambio radical de paradigma acerca del papel del derecho, surge cuando se redescubre el significado de la Constitución como límite y vínculo de los poderes públicos, cuando se redescubre el valor de la Constitución como norma dirigida a garantizar la división de poderes y los derechos fundamentales de todos. Enfatiza que la constitucionalización rígida de los derechos fundamentales, propia de un Estado Constitucional y el Estado ecuatoriano lo es, según definición del Texto Fundamental de Montecristi ${ }^{36}$ - ha insertado en la democracia una dimensión sustancial, que permite superar el enfoque formalista o procedimental de democracia en tanto método de formación de las decisiones colectivas o conjunto de reglas que atribuyen al pueblo el poder -directo o a través de sus representantes- de asumir decisiones. La democracia constitucional incluye, junto a la dimensión política o formal, también una dimensión sustancial, dado que se refiere a los contenidos o sustancia de las decisiones en armonía con los derechos fundamentales garantizados por la norma constitucional.

Ferrajoli sostiene que los derechos fundamentales -elemento esencial en un Estado constitucional- conforman la parte sustancial de una democracia, ya que disponen lo que el gobierno debe hacer (en el caso, por ejemplo de los derechos sociales) o no puede hacer (en el caso de los derechos de libertad). Los derechos fundamentales están garantizados en el Estado constitucional y sustraídos a la disponibilidad del mercado y de la política, forman la esfera de lo indecidible, y actúan como factores no sólo de legitimación sino también, y sobre todo, como factores de deslegitimación de las decisiones y de las no decisiones.

La concepción de la democracia constitucional como modelo normativo - sostiene Ferrajoli- se halla articulada en varias dimensiones, correspondientes a otras tantas clases de derechos: la democracia política, asegurada por las garantías de los derechos políticos; la democracia civil, asegurada por las garantías de los derechos civiles; la democracia liberal (o liberal-democracia) asegurada por las garantías de los derechos de libertad; la democracia social

\footnotetext{
${ }^{35}$ R.O. No. 811 de 17 de octubre de 2012.

36 "El Ecuador es un Estado constitucional de derechos y justicia, social, democrático, soberano, independiente, unitario, intercultural, plurinacional y laico” (Art. 1, Constitución de la República de 2008).
} 
(o social-democracia), asegurada por las garantías de los derechos sociales; por lo que el garantismo, tomado en sus cuatro dimensiones -política, civil, liberal y social, según la clase de derechos garantizados- puede ser muy bien considerado la otra cara del constitucionalismo y como el presupuesto jurídico de la efectividad de la democracia.

Robert Alexy (2009) sostiene que el Estado constitucional democrático se caracteriza por los principios fundamentales de la dignidad humana, la libertad, la igualdad y los principios relativos a la estructura y los fines del Estado de derecho, democrático y social.

La democracia constitucional, según el enfoque de Pedro Salazar (2011), es un modelo de organización político-jurídica en el que confluyen diversas tradiciones del pensamiento político moderno y que persigue en un solo momento dos objetivos analíticamente distintos: limitar el poder político y distribuirlo entre los ciudadanos, y detrás de esta doble finalidad reposan los derechos fundamentales - de libertad, políticos y sociales- de los individuos que integran la colectividad política.

Como se ha señalado en este trabajo, la Constitución de 2008 pone en vigencia dos paradigmas que innovan el orden jurídico y político del Ecuador: el Estado constitucional de derechos y justicia y el neoconstitucionalismo, ambos articulados con el modelo de democracia y el diseño institucional participativo que la configura, en el marco de un constitucionalismo fuertemente principialista y garantista, expresión de un proyecto de transformación pacífica y democrática, que dota a la ciudadanía de una caja de herramientas de participación y de democracia directa y asigna a los jueces el rol estratégico en la legitimación y legitimidad del modelo.

\section{Innovación social y desarrollo.}

La innovación es el proceso mediante el cual el conocimiento nuevo o existente se convierte en valor para beneficio de los individuos, grupos o comunidades. Un sistema de innovación es una red en la que los actores interactúan e intercambian conocimiento codificado y conocimiento tácito para emprender actividades de innovación. La innovación es la habilidad para resolver problemas y superar cuellos de botella en los países en vías de desarrollo. La innovación no se trata simplemente de aprender la manera de hacer algo de una mejor forma sino de cómo hacer algo de modo diferente.

El conocimiento es el recurso esencial en un sistema de innovación y la red proporciona los canales a través de los cuales fluye el conocimiento. Dicho sistema se basa en relaciones complejas que involucran el aprendizaje, un proceso fundamental en la innovación. Muchos actores interactúan en un entorno específico moldeado por la historia, la cultura y las relaciones sociales. La dinámica resultante caracteriza un sistema de innovación específico.

Un marco para comprender la innovación debe tomar en cuenta la inestabilidad, las desigualdades y las heterogeneidades que se presentan cuando la innovación ocurre en un entorno en vías de desarrollo, como el caso ecuatoriano, bajo la premisa respecto de la cual, la innovación que no está basada en I+D puede ocurrir mediante la adaptación de tecnologías o 
prácticas existentes, mediante el aprendizaje por el hacer o por el uso y como resultado de la movilidad de conocimiento y las capacidades de la gente.

No existe un camino único que conduzca a la innovación para el desarrollo. Las estrategias de innovación son tan diversas como los retos que las sociedades enfrentan en distintas partes del mundo. La diversidad de los países regiones, sectores y empresas se debe tratar, reconocer y aceptar para avanzar en el pensamiento acerca de las estrategias de innovación: la heterogeneidad se debe abordar a nivel nacional. En el proceso del diseño de las estrategias de innovación existe la necesidad de prestar atención al contexto, los antecedentes, la dependencia de la trayectoria, las consideraciones culturales y los regímenes políticos existentes de los países de manera individual.

Los estudios iniciales en lo que se refiere al proceso de recuperación de un país sugirieron que existen atajos tecnológicos que podrían permitir a los países en vías de desarrollo llegar a la etapa de desarrollo de las economías avanzadas. La principal manera en que un país podría llegar a esta etapa es asimilando y adaptando tecnologías maduras (Utterback y Abernathy, 1975; Kim, 1980, 1997). De hecho, algunos consideraron el subdesarrollo como una ventaja potencial, ya que proporciona a los países en vías de desarrollo la oportunidad de extraer lecciones valiosas a partir de las experiencias de las naciones industrializadas y avanzar a pasos agigantados a etapas de desarrollo más eficientes.

El proceso de innovación, y en particular su carácter sistémico, aún no se comprenden del todo (Edquist, 2005). No obstante, la idea de que la innovación ocurre dentro de un "sistema" refleja el reconocimiento de que la conversión del conocimiento en un valor es perfilada por factores estructurales, institucionales y sociales.

\section{Los principales componentes de un sistema de innovación.}

Las organizaciones e instituciones, al igual que las relaciones que las vinculan, son los principales componentes de un sistema de innovación. Las organizaciones son estructuras formales que se crean de manera consciente y tienen un propósito explícito. Hay jugadores o actores. Algunas organizaciones importantes del sistema de innovación son las empresas, universidades, organizaciones de capital de riesgo y agencias de creación de políticas. Las instituciones son conjuntos de hábitos comunes, normas, rutinas, prácticas establecidas, reglas o leyes que regulan las relaciones e interacciones entre los individuos, grupos y organizaciones. Son "las reglas del juego". Los vínculos son las interacciones que ocurren dentro y a través de las organizaciones e instituciones.

\section{Sistemas de conocimiento en los países en vías de desarrollo.}

La coexistencia del conocimiento "tradicional" o "autóctono" y el conocimiento "científico" o "moderno" es una característica típica de los países en vías de desarrollo. Los sistemas de conocimiento moderno representan la creación e intercambio de conocimiento formalmente organizado y basado en la ciencia. Los sistemas de conocimiento tradicionales tienen sus raíces principalmente en las comunidades locales, y el conocimiento se transmite de una generación a la otra. 
Las actividades basadas en la ciencia representan una pequeña parte de las actividades económicas en las regiones en vías de desarrollo. Cada vez se reconoce con mayor fuerza que el conocimiento tradicional desempeña un papel importante en el sustento de las poblaciones de los países en vías de desarrollo (Bell, 2006), en especial en África. Sin embargo, los sistemas de conocimiento tradicionales no están bien articulados, lo que les dificulta ser proactivos y adaptarse a nuevas demandas de conocimiento. Además, los vínculos entre los sistemas de conocimiento modernos y tradicionales tienden a ser débiles (Bell, 2007). Por tanto, uno de los principales retos del enfoque de los sistemas de innovación es encontrar mecanismos para fortalecer las interacciones que promueven el flujo de conocimiento dentro y entre los sistemas de conocimiento tradicionales y modernos. Bell (2006) argumenta que se deberían dirigir esfuerzos hacia la articulación e integración de los sistemas de conocimiento, tradicionales y modernos, en un proceso interactivo de innovación.

\section{Transformación de los sistemas de innovación.}

Los sistemas de innovación se perfilan en gran medida por las condiciones sociales, institucionales e históricas. Por tanto, la transformación de los sistemas de innovación depende de los cambios en estas condiciones, las cuales son diversas, múltiples y están interconectadas.

\section{Innovación sistémica de la ciencia jurídica y de la institucionalidad estatal al servicio de la sociedad y la naturaleza.}

Innovar, en el contexto del presente trabajo, significa la reconstrucción de la ciencia jurídica y el rediseño de la institucionalidad estatal, la justicia y la democracia, para poner estos factores de desarrollo al servicio de los intereses sociales y nacionales, mediante una aproximación distinta al fenómeno jurídico, desde perspectivas interculturales e intedisciplinarias y con abordajes metodológicos, epistemológicos y gnoseológicos distintos, enfocándolo como relación social histórica, superando el colonialismo jurídico del positivismo normativista que ha limitado el desarrollo del pensamiento jurídico y ha postergado la plasmación de la justicia sustancial y los derechos de las mayorías nacionales.

Y en este innovador enfoque de la ciencia jurídica, la Constitución de 2008, la jurisprudencia constitucional y la actuación del aparato de justicia, tienen roles fundamentales que cumplir. La Corte Constitucional y la Academia son actores protagónicos en este nuevo cauce de la ciencia jurídica para desentrañar el carácter complejo y dialéctico de la realidad jurídica, fundamentar, desarrollar y materializar los derechos de los ciudadanos, los pueblos y la naturaleza.

\section{Conclusiones.}

La jurisprudencia constitucional y los precedentes obligatorios y vinculantes de la Corte Constitucional tienen incidencia fundamental en los ámbitos sociales, jurídicos y políticos, como instrumento de innovación social y desarrollo, en el marco de los nuevos paradigmas del ordenamiento jurídico ecuatoriano, atento el potencial emancipatorio del derecho y su papel en el 
proceso de institucionalización del proyecto de transformaciones diseñado por la Constitución de 2008.

La Corte Constitucional tiene un rol protagónico en el proceso de constitucionalización de la cultura jurídica y de la vida cotidiana del país, mediante la creación de un sólido acervo jurisprudencial que consolide la transformación del sistema de fuentes del derecho y la resolución de los conflictos sociales más relevantes del país.

Los jueces (la judicatura), abogados (el foro) y docentes del derecho (la academia), que son también actores principales en la consolidación del nuevo orden jurídico político que consagra la Constitución, deben asignar mayor protagonismo a la jurisprudencia constitucional, a fin de materializar los paradigmas del Estado constitucional, el neoconstitucionalismo, la constitucionalización del derecho y la constitucionalización de la justicia, instituidos por el Texto Fundamental.

En razón de que la conversión de la jurisprudencia constitucional en fuente de derecho pasa por el proceso previo de conocimiento de las decisiones de la Corte Constitucional por parte de los operadores jurídicos, es necesaria su profusa difusión en los diferentes contextos de la práctica del derecho: la judicatura, el foro y la academia.

Los jueces deben ser formados en la nueva cultura de la constitucionalización de la justicia y la Corte Constitucional debe desplegar una labor de difusión de sus decisiones en todos los despachos judiciales del país, a fin de lograr que los operadores judiciales motiven más y mejor sus sentencias invocando la jurisprudencia y los precedentes emanados del máximo órgano de interpretación y control de la Constitución.

Los abogados deben diseñar sus estrategias de defensa en función de precedentes constitucionales, a cuyo efecto, es necesario que tanto la academia como el gremio profesional promuevan la formación compatible con el nuevo sistema de manejo de las fuentes del ordenamiento jurídico.

Los docentes del derecho deben enfocar su enseñanza a la luz de la jurisprudencia constitucional y los precedentes vinculantes, a fin de lograr que la formación jurídica sea más metodológica y argumentativa con base en la jurisprudencia y en los precedentes emanados de la Corte Constitucional.

Es necesario diseñar y aplicar políticas públicas concertadas entre Corte Constitucional, Consejo de la Judicatura, Universidades y Gremios de Abogados, a fin de promover la nueva cultura jurídica basada en la jurisprudencia constitucional y su uso social, político y jurídico, en el proceso de las transformaciones orientadas por el Texto Constitucional.

Los derechos humanos, llamados también derechos fundamentales, derechos naturales, derechos públicos subjetivos, libertades públicas, derechos morales, que traducen en el fondo, ideales de dignidad, de justicia y de libertad, encuentran en la jurisprudencia constitucional, su más adecuada vía de plasmación. 
La notable innovación clasificatoria en derechos del buen vivir (agua y alimentación, ambiente sano, comunicación e información, cultura y ciencia, educación, hábitat y vivienda, salud, trabajo y seguridad social), derechos de las personas y grupos de atención prioritaria (adultas y adultos mayores, jóvenes, movilidad, mujeres embarazadas, niñas, niños y adolescentes, personas con discapacidad, personas con enfermedades catastróficas, personas privadas de libertad, personas usuarias y consumidoras), derechos de las comunidades, pueblos y nacionalidades (indígenas, afroecuatorianos, montubios), derechos de participación, derechos de libertad, derechos de la naturaleza y derechos de protección, traduce la tendencia emancipatoria del Derecho y de la administración de justicia, donde la jurisprudencia constitucional constituye estrategia clave para el desarrollo progresivo del contenido y la materialización de los derechos consagrados en la Constitución.

El modelo de democracia directa, inclusiva, participativa, que nació como producto de la Asamblea Constituyente de Montecristi sólo es posible sostenerse por el involucramiento de todos los miembros de la sociedad en los procesos de decisión, diagnóstico, priorización e identificación de los problemas y de cómo asignar los recursos para resolver esos problemas. En este sentido, la jurisprudencia constitucional y su uso por parte de los jueces, se convierte en factor coadyuvante para materializar los derechos constitucionales, dando contenido sustancial a la democracia inclusiva y de oportunidades concebida en la Carta Fundamental.

La democracia, que debe construirse según los postulados constitucionales vigentes, es una democracia que debe promover el desarrollo integral, integrador y participativo, y en ese orden, la jurisprudencia constitucional es factor de innovación social y de desarrollo, porque involucra, a partir de su utilización por parte de los jueces, a todo los estamentos de la sociedad y del Estado, en la gran tarea de superar la brecha entre las promesas constitucionales y las vivencias cotidianas de la gente.

Existen grandes posibilidades y al mismo tiempo grandes barreras, limitaciones o restricciones para los mecanismos de democracia directa garantizados en la Constitución de 2008. Para acortar la brecha entre el deber ser de la participación y el ser y el quehacer de la participación real, es necesario propiciar espacios para la aplicación cotidiana de las herramientas que reconoce la Constitución en los diferentes espacios públicos. Se requiere liderazgo y voluntad política, por una parte; y, adecuada organización del proceso participativo, por otra.

La legitimidad del proceso democrático se basa en la transparencia, la rendición de cuentas y sobre todo, en la participación ciudadana. La implementación de los instrumentos y los procesos participativos previstos en la Constitución constituyen un enorme reto en el Ecuador. No es suficiente la diagramación constitucional de los mecanismos de participación ciudadana que diseña el Texto Constitucional, es necesario superar las barreras estructurales que impiden que esos mecanismos de participación ciudadana se viabilicen en la práctica, y en este objetivo, la jurisprudencia constitucional juega un rol fundamental para la concreción de los derechos, y en especial, los derechos de participación.

Mediante el uso social, jurídico y político de la jurisprudencia constitucional, es posible institucionalizar los mecanismos de participación ciudadana en y durante todo el ciclo de la 
política pública, a fin de garantizar adecuados niveles de estabilidad política y la construcción de una cultura política participativa que se arraigue en la conciencia social. El éxito del modelo de democracia participativa y de la eficacia de las herramientas de participación ciudadana depende de la cultura política, la acción de los movimientos sociales, la voluntad política de los gobernantes y el sentido de compromiso colectivo frente a la democracia participativa.

Es necesario institucionalizar espacios que permitan a la ciudadanía acceso a las instancias de gobierno nacional y local. Las organizaciones políticas y los líderes de todos los niveles de gobierno deben desplegar todo esfuerzo para que la sociedad recupere la confianza en la política y sean factor coadyuvante de la gobernabilidad y de la gobernanza, la sostenibilidad de los gobiernos y la participación profunda de la sociedad civil organizada, haciendo posible la democratización de la democracia, es decir, la construcción de una democracia de "alta intensidad", posibilitando, de este modo, reducir los riesgos de crisis del sistema político. Y en este ámbito, la jurisprudencia constitucional y la labor de los jueces, tienen un rol decisorio como garantes de los derechos de participación.

La jurisprudencia constitucional, en el nuevo Estado constitucional de derechos y justicia diseñado por la Constitución de 2008 es un potente instrumento social, político y jurídico en manos de los jueces y de la ciudadanía, para favorecer los cambios y las innovaciones sociales en democracia que entraña el proyecto político contenido en la Constitución de 2008.

Mediante el uso social de la jurisprudencia constitucional, es posible conservar las conquistas sociales y asegurar las transformaciones estructurales en una sociedad profundamente inequitativa, aumentar los niveles de exigibilidad de los derechos y una ciudadanía volcada a vivir realmente los derechos constitucionales, en un proceso permanente de transformación social basado en una política constitucional y una justicia progresista, que materialice los principios y valores de la Constitución. Mediante el uso jurídico, la jurisprudencia constitucional es una herramienta valiosa para garantizar la igualdad procesal, predictibilidad, uniformidad de la actuación de la justicia, la seguridad jurídica, y procurar acercar a la justicia a los problemas concretos e intereses sociales de la población. Mediante el uso político, los jueces otorgan legitimidad a la democracia y hace posible convertir a la justicia en una herramienta dinámica para la materialización de la Constitución y los límites del poder.

La ciencia jurídica, los procesos tecnológicos e institucionales y la innovación, conectados al potencial emancipatorio del Derecho, enfocado éste como praxis social compleja de la vida de los pueblos y el reconocimiento de su potencial transformador para satisfacer las demandas sociales reivindicatorias, y en particular las necesidades humanas básicas del buen vivir, fundamentan los contornos de la dialéctica interrelación ciencia-tecnología-innovación, al servicio integral de la sociedad y la naturaleza.

\section{Bibliografía}

Alexy, Robert (2009) Los derechos fundamentales en el Estado constitucional democrático, en Neoconstitucionalismo (s). Madrid: Editorial Trotta.

Andrade, Santiago (2009) La Función Judicial en la vigente Constitución de la República, en "La nueva Constitución del Ecuador". Quito: Corporación Editora Nacional. 
Ávila, Luis Fernando (2009). La constitucionalización de la administración de justicia en la Constitución de 2008 en "Constitución de 2008 en el contexto andino". Quito: Corte Constitucional.

Ávila, Luis Fernando (2013) El precedente constitucional: teoría y praxis. Bogotá: Grupo Editorial Ibáñez.

Ávila, Ramiro (2009) Caracterización de la Constitución de 2008. Visión panorámica de la Constitución a partir del Estado Constitucional de Derechos y Justicia, en "La Nueva Constitución del Ecuador". Quito: Corporación Editora Nacional.

Bernal Pulido, Carlos (2009). El neoconstitucionalismo y la normatividad del derecho, Bogotá: Universidad Externado de Colombia.

Carbonell, Miguel, editor (2007). Teoría del neoconstitucionalismo, Madrid: Editorial Trotta.

Carbonell, Miguel, editor (2009) Neoconstitucionalismo (s), Madrid: Editorial Trotta.

Chinchilla, Tulio (2009) ¿Qué son y cuáles son los derechos fundamentales?, Bogotá: Ara Editores.

Comanducci, Paolo (2009) Formas de (Neo) Constitucionalismo: un análisis metateórico, en Neoconstitucionalismo (s), Ed. Carbonell. Madrid: Editorial Trotta.

De Sousa Santos, Boaventura (2004) Reinventar la democracia. Reinventar el Estado. Quito: Ediciones Abya-Yala.

De Sousa Santos, Boaventura (Coord.) (2005) Democratizar la democracia. México, D.F.: Fondo de Cultura Económica.

De Sousa Santos, Boaventura (2009) Sociología jurídica crítica: para un nuevo sentido común en el Derecho. Madrid: Editorial Trotta.

De Sousa Santos, Boaventura (2012) Derecho y emancipación. Quito: Centro de Estudios y Difusión, Corte Constitucional del Ecuador.

Dworkin, Ronald (2008) La democracia posible. La democracia para un nuevo debate político. Buenos Aires: Paidós.

Ferrajoli, Luigi (2009) Derechos y Garantías, La Ley del más débil, sexta edición, Madrid: Editorial Trotta.

Ferrajoli, Luigi (2008) Democracia y garantismo. Madrid: Editorial Trotta.

Ferrajoli, Luigi (2011) Poderes salvajes. La crisis de la democracia constitucional. Madrid: Editorial Trotta.

Ferrajoli, Luigi (2014) La democracia a través de los derechos. El constitucionalismo garantista como modelo teórico y como proyecto político. Madrid: Editorial Trotta.

Fioravanti, Maurizio (2009) Los derechos fundamentales, Madrid: Editorial.

Gil Domínguez, Andrés (2009) Escritos sobre neoconstitucionalismo, Buenos Aires: Ediar. 
Guastini, Ricardo (2010) Interpretación, Estado y Constitución, Lima: Ara Editores.

Häberle, Peter (1994). El concepto de los derechos fundamentales, en "Problemas actuales de los derechos fundamentales", Madrid: Ed. de José Ma. Sauca, Universidad Carlos III.

Nogueira, Humberto (2009). La interpretación constitucional de los derechos humanos, Lima: Ediciones Legales.

Peña, Antonio Manuel (1997). La garantía en el Estado constitucional de derecho, Madrid: Editorial Trotta.

Polo Blanco, Jorge (2016) Teoría de la dependencia y colonialidad del poder. Dos ángulos de una misma dominación, en Revista San Gregorio No. 11, volumen 1, enero-junio 2016.

Prieto Sanchís, Luis (2009). Justicia Constitucional y Derechos Fundamentales, Madrid: Editorial Trotta.

Rolla, Giancarlo (2011). La garantía de los derechos fundamentales en el constitucionalismo contemporáneo, en "Horizontes contemporáneos del Derecho Procesal Constitucional", tomo 1, coord. Eto Cruz, Gerardo, Lima: Editorial Adrus.

Sagüés, Néstor Pedro (2011). La interpretación judicial de la Constitución, segunda edición, Buenos Aires: LexisNexis.

Salamanca, Antonio (2015) La investigación jurídica intercultural e interdisciplinar. Metodología, epistemología, gnoseología y ontología, IAEN: Quito.

Salazar, Pedro (2011) La democracia constitucional una radiografía teórica. México: Fondo de Cultura Económica-UNAM.

Starck, Christian (2011). Jurisdicción Constitucional y Derechos Fundamentales, Madrid: Editorial Dykinson.

SENPLADES (2013) Plan Nacional de Desarrollo/Plan Nacional para el Buen Vivir 2013-2017. Quito: Secretaría Nacional de Planificación y Desarrollo.

Tribunal Constitucional Del Ecuador (2007), Un cambio ineludible: La Corte Constitucional, Memorias del Taller Internacional, Quito.

Tribunal Constitucional (2008). Desafíos constitucionales, La Constitución ecuatoriana del 2008 en perspectiva, Serie Justicia y Derechos Humanos, Neoconstitucionalismo y Sociedad, Quito.

Zagrebelsky, Gustavo (2009). El derecho dúctil, Madrid: Editorial Trotta.

Fuentes Normativas y Jurisprudenciales del Ecuador:

- $\quad$ Constituciones de la República del Ecuador: 1830-2008;

- $\quad$ Constitución de la República del Ecuador 2008 (R.O. 449, 20-X-2008);

- Resolución sobre el ejercicio de competencias y la transformación del Tribunal Constitucional en Corte Constitucional (R.O. 451, 22-octubre-2008);

- $\quad$ Sentencia Interpretativa de la Corte Constitucional 001-08-SI-CC (R.O. 479, 2-diciembre-2008);

- $\quad$ Ley Orgánica de Garantías Jurisdiccionales y Control Constitucional (R.O. 52-2S, 22-X-2009). 